\title{
Impact of cancer breast distance from skin surface on axillary lymph node metastasis in female patients with early breast cancer: correlation between radiological and pathological distance
}

\author{
Mohamed S Essa \\ Benha University Faculty of Medicine \\ khaled S Ahmad ( $\sim$ Khaled.ahmad.md@gmail.com ) \\ Prince Mohammed Bin Abdul Aziz Hospital \\ Mohamed E Zayed \\ Benha University Faculty of Medicine \\ Mohamed H Faheem \\ Benha University Faculty of Medicine \\ Rana Abdalla \\ Benha University Faculty of Medicine
}

\section{Research article}

Keywords: Early cancer breast cancer, Distance from the skin surface, Axillary lymph node metastasis, Ultrasonography in cancer breast

Posted Date: May 27th, 2020

DOI: https://doi.org/10.21203/rs.3.rs-30258/v1

License: (c) (1) This work is licensed under a Creative Commons Attribution 4.0 International License.

Read Full License 


\section{Abstract}

Background: The aim of this study is to evaluate the relation between proximity of breast cancer to the skin and incidence of axillary nodal metastasis in order to clarify a new guideline in treatment of early cancer breast.

Methods: This study includes 50 female patients with early cancer breast (T1 and T2). All patients underwent breast ultrasonography (U/S) with special confirmation on the breast cancer distance from skin surface (radiological distance) in addition to pathological assessment of the distance (pathological distance) after surgical excision and its correlation with radiological distance. Breast conservative surgery (BCS) with axillary clearance was done for 46 patients, while 4 patients underwent modified radical mastectomy (MRM).

Results: This study showed that the more proximal the cancer from the skin, the higher the incidence of axillary lymph node (LN) metastasis, and the cut off radiological distance was $2.6 \mathrm{~cm}$ from the skin while cut off pathological distance was $2.56 \mathrm{~cm}$. It also proved that $\mathrm{U} / \mathrm{S}$ is an accurate and reliable method in a assessing the breast cancer distance.

Conclusion: Our results revealed that cancer breast cancers located closer to the skin surface have a higher incidence of axillary lymph node metastasis.

\section{Background}

Inspite of pathological features and molecular biology of cancer breast, the status of axillary lymph nodes is one of the most reliable and important prognostic factors in addition to its role in guidance of adjuvant cancer breast treatment ${ }^{[1]}$.

Axillary lymph node dissection (ALND) has been a routine part of cancer breast treatment for long time because it provides data about the status of axillary LN (prognostic role) in addition to removal of axillary tumors in patients presented with positive LNs (therapeutic role). Incidence of postoperative complications of ALND are $15-30 \%$ and include postoperative bleeding, local swelling, numbness, decrease range of motion, wound infection, neuropathy, and chronic lymphedema ${ }^{[2]}$. So predication of axillary nodal status before surgery is essential to prepare patient psychologically for ANLD and in planning for immediate breast reconstruction in addition to avoidance of ANLD if axilla is negative for metastasis ${ }^{[3]}$.

Several studies have reported that the lymphatic pathway present in the dermis is responsible for cancer breast metastatic pathway and suggest that the parenchyma of the breast is not rich in lymphatic plexus than that in the superficial dermal and subdermal layers ${ }^{[4]}$.

Only few studies have investigated the relation between the breast cancer distance from skin surface and axillary nodal deposits. Ultrasonography $(\mathrm{U} / \mathrm{S})$ is a more accurate tool for detection of the distances from 
the skin. Distances of cancer breast from the skin on mammography are subject to variability because of patient positioning ${ }^{[5,6]}$.The aim of our study is to evaluate the relation between breast cancer distance from the skin and axillary LN metastasis

\section{Methods}

\section{Study Design:}

This prospective study includes 50 female patients with early cancer breast who were diagnosed and managed at General Surgery Department, Benha University Hospital from April 2017 to October 2019.

\section{Inclusion criteria:}

1. Female patients with $\mathrm{T} 1$ or $\mathrm{T} 2$ cancer breast.

2. Patients who have tumors visible on breast ultrasound or mammography.

\section{Exclusion criteria:}

1. Locally advanced breast cancer $(\mathrm{T} 3, \mathrm{~T} 4)$.

2. Metastatic cancer breast.

3. Multicentric breast cancer.

4. Benign breast lumps.

5. Women who received neoadjuvant chemotherapy.

After approval of the study by Benha Faculty of Medicine Ethical Committee (No: RC 2.3.2020) and obtaining written informed consent from the patients for the participation in the study. Patients were fully informed about the hazards and benefits of the surgery. The Patients assessed by a multidisciplinary team (includes one or more specialized representative from general surgery, pathology, radiology, radiotherapy, and medical oncology) and patients enrolled in the study if they fulfilled our inclusion criteria. All patients underwent the following:

\section{1-Full detailed history}

\section{2-Clinical examination}

\section{3-Laboratory investigations:}

Complete blood picture (CBC), fasting and postprandial blood glucose liver function tests, renal function tests.

\section{4-Radiological investigations (measurement of cancer distance from the skin)}


Both breasts were examined by radiologist using US device equipped with linear transducer for threedimensional image $(5-12 \mathrm{MHz})$. In all patients the distance was measured perpendicularly from the skin surface to the anterior hyopechoic edge of the tumor before the biopsy. All US images are recorded and subsequently taken for retrospective measurements of breast cancer proximity from surface of the skin [Figure 1]. Bilateral mammography also done.

5- Metastatic work up: computed tomography (CT) of chest and abdomen in addition to bone scan if indicated

\section{6-Pathological evaluation (measurement of cancer distance from the skin)}

Wide local excision (WLE) of the breast lump, is done with an elliptical incision of the overlying skin then it is sent for histopathological assessment with measurement of pathological distance [Figure2]. The specimen is oriented by stitches to detect the margins for further management.

\section{Operative plan:}

Breast conservative surgery (BCS) or modified radical mastectomy (MRM) was explained to the patient preoperatively and informed consent was taken. Type of surgery done for our patients were conducted based on type of histopathology, size of the mass, breast size, site of the mass and socioeconomic status. Patients in our study underwent either BCS with axillary clearance or MRM [Figure2].

A final pathology report is included with special emphasis on the safety margins, histopathological type, distance from the skin and number of involved axillary lymph nodes in addition to the immunohistochemical assay for oestrogen, progesterone receptors status (ER and PR) and Her2/neu expression in the specimen. In case of BCS, if the safety margin is inadequate $(\mathbb{\nabla} \mathrm{cm})$ redo excision is done.

After fulfillment of the patients data, they are informed regarding the dates of the regular follow-up and they were referred to the outpatient oncology clinic for further management plan regarding radiotherapy, chemotherapy in addition to hormonal therapy according to the final pathology report.

\section{Primary endpoint:}

Evaluation of the prognostic importance of assessing the proximity of cancer breast to the skin and incidence of axillary LN metastasis.

\section{Secondary outcomes:}

Evaluating the sensitivity of breast U/S and pathological assessment in detecting the distance between the cancer breast and the skin.

\section{Statistical analysis:}


Data were statistically described in terms of mean \pm standard deviation $( \pm S D)$, median and range, or frequencies (number of cases) and percentages when appropriate. Comparison of numerical variables between the study groups was done using Kruskal Wallis test. Within group comparison of distance was done using paired $t$ test. For comparing categorical data, Chi-square $\left(c^{2}\right)$ test was performed. Exact test was used instead when the expected frequency is less than 5. Accuracy was represented using the terms sensitivity, and specificity. Receiver operator characteristic (ROC) analysis was used to determine the optimum cut off value for the studied diagnostic markers. $p$ values less than 0.05 was considered statistically significant. All statistical calculations were done using computer program IBM SPSS (Statistical Package for the Social Science; IBM Corp, Armonk, NY, USA) release 22 for Microsoft Windows.

\section{Results}

This prospective study includes 50 female patients presented with early cancer breast (T1 and T2). BCS was done for 46 patients, while 4 patients underwent MRM due to centrally located tumors, tumors that are large in relation to small breast size or sometimes patient wishes. There was no statistically significant difference between the age of the patient and incidence of axillary lymph node metastasis, ( $p$ value $=0.165$ ) [Table 1]. There was no significant statistical variation between the location of tumor and the incidence of axillary nodal metastasis, $(p$ value $=0.175$ ). The relation between US BIRAD classification of breast mass and incidence of axillary lymph node metastasis showed no statistically significant difference, $(p$ value $=0.486)$. There was no significant variation between tumor size $(T$ stage $)$ and incidence of nodal metastasis. (P value $=0.758$ ). Mean size of the tumor was $2.65 \mathrm{~cm}$. All data regarding relation of anatomical location, BIRAD and T stage with axillary LN metastasis are summarized in Table 2. Regarding hormonal status of the tumor including ER and PR in addition to HER2 there was no statistically significant variation between the hormonal status and incidence of axillary nodal deposits, $(P$ value, $\mathrm{ER}=0.267, \mathrm{PR}=0.124, \mathrm{HER} 2=0.542$ ), [Table 3].

Table (1): Relation between patient's age and axillary nodal metastasis 


\begin{tabular}{||c|c|c||}
\hline \hline \multirow{4}{*}{0} & & Age \\
\hline \multirow{4}{*}{ 1 } & Number & 33 \\
\cline { 2 - 3 } & Mean & 51.87 \\
\cline { 2 - 3 } & SD & 6.483 \\
\cline { 2 - 3 } & Median & 51.00 \\
\hline \multirow{4}{*}{2} & Number & 8 \\
\cline { 2 - 3 } & Mean & 46.78 \\
\cline { 2 - 3 } & SD & 4.734 \\
\cline { 2 - 3 } & Median & 46.50 \\
\hline \multirow{3}{*}{2} & Number & 9 \\
\cline { 2 - 3 } & Mean & 52.67 \\
\cline { 2 - 3 } & SD & 8.570 \\
\cline { 2 - 3 } & Median & 52.00 \\
\hline \multirow{2}{*}{ Total } & Number & 50 \\
\hline \hline
\end{tabular}

SD: Standard deviation

Table (2): Relation between breast tumor location, tumor BIRAD, breast tumor size (T) and axillary nodal metastasis. 


\begin{tabular}{|c|c|c|c|c|c|c|c|}
\hline & & & & \multicolumn{3}{|c|}{$\mathbf{N}$} & \multirow[t]{2}{*}{ Total } \\
\hline & & & & 0 & 1 & 2 & \\
\hline \multirow[t]{15}{*}{ Tumor location } & \multirow{3}{*}{\multicolumn{2}{|c|}{ central }} & Count & 4 & 0 & 0 & 4 \\
\hline & & & $\%$ within tumor quadrant & $100.0 \%$ & $0.0 \%$ & $0.0 \%$ & $100.0 \%$ \\
\hline & & & $\%$ within $\mathbf{N}$ & $12.1 \%$ & $0.0 \%$ & $0.0 \%$ & $8.0 \%$ \\
\hline & \multirow{3}{*}{\multicolumn{2}{|c|}{ lower inner quadrant }} & Count & 2 & 4 & 1 & 7 \\
\hline & & & $\%$ within tumor quadrant & $28.5 \%$ & $57.1 \%$ & $14.2 \%$ & $100.0 \%$ \\
\hline & & & \% within $\mathrm{N}$ & $6.06 \%$ & $50.0 \%$ & $11.1 \%$ & $14.0 \%$ \\
\hline & \multirow{3}{*}{\multicolumn{2}{|c|}{ lower outer quadrant }} & Count & 4 & 2 & 2 & 8 \\
\hline & & & \% within tumor quadrant & $50.0 \%$ & $25.0 \%$ & $25.0 \%$ & $100.0 \%$ \\
\hline & & & $\%$ within $\mathbf{N}$ & $12.1 \%$ & $25.0 \%$ & $22.2 \%$ & $16.0 \%$ \\
\hline & \multirow{3}{*}{\multicolumn{2}{|c|}{ upper inner quadrant }} & Count & 3 & 2 & 1 & 6 \\
\hline & & & $\%$ within tumor quadrant & $50.0 \%$ & $33.3 \%$ & $16.6 \%$ & $100.0 \%$ \\
\hline & & & $\%$ within $\mathbf{N}$ & $9.09 \%$ & $25.0 \%$ & $11.1 \%$ & $12.0 \%$ \\
\hline & \multirow{3}{*}{\multicolumn{2}{|c|}{ upper outer quadrant }} & Count & 20 & 0 & 5 & 25 \\
\hline & & & $\%$ within tumor quadrant & $80.0 \%$ & $0.0 \%$ & $20.0 \%$ & $100.0 \%$ \\
\hline & & & $\%$ within $\mathbf{N}$ & $60.6 \%$ & $0.0 \%$ & $55.5 \%$ & $50.0 \%$ \\
\hline \multirow{3}{*}{\multicolumn{3}{|c|}{ Total }} & Count & 33 & 8 & 9 & 50 \\
\hline & & & $\%$ within tumor quadrant & $66.0 \%$ & $16.0 \%$ & $18.0 \%$ & $100.0 \%$ \\
\hline & & & $\%$ within $\mathbf{N}$ & $100.0 \%$ & $100.0 \%$ & $100.0 \%$ & $100.0 \%$ \\
\hline \multirow{12}{*}{\multicolumn{2}{|c|}{ BIRAD }} & \multirow{3}{*}{$4 \mathrm{~A}$} & Count & 2 & 0 & 0 & 2 \\
\hline & & & $\%$ within BIRAD & $100.0 \%$ & $0.0 \%$ & $0.0 \%$ & $100.0 \%$ \\
\hline & & & $\%$ within $\mathbf{N}$ & $6.3 \%$ & $0.0 \%$ & $0.0 \%$ & $4.0 \%$ \\
\hline & & \multirow{3}{*}{$4 B$} & Count & 6 & 2 & 0 & 8 \\
\hline & & & $\%$ within BIRAD & $75.0 \%$ & $25.0 \%$ & $0.0 \%$ & $100.0 \%$ \\
\hline & & & $\%$ within $\mathrm{N}$ & $18.8 \%$ & $22.2 \%$ & $0.0 \%$ & $16.0 \%$ \\
\hline & & \multirow{3}{*}{$4 c$} & Count & 11 & 1 & 4 & 16 \\
\hline & & & $\%$ within BIRAD & $68.8 \%$ & $6.3 \%$ & $25.0 \%$ & $100.0 \%$ \\
\hline & & & $\%$ within $\mathrm{N}$ & $34.4 \%$ & $11.1 \%$ & $44.4 \%$ & $32.0 \%$ \\
\hline & & \multirow{3}{*}{5} & Count & 13 & 6 & 5 & 24 \\
\hline & & & $\%$ within BIRAD & $54.2 \%$ & $25.0 \%$ & $20.8 \%$ & $100.0 \%$ \\
\hline & & & $\%$ within $\mathrm{N}$ & $40.6 \%$ & $66.7 \%$ & $55.6 \%$ & $48.0 \%$ \\
\hline \multirow{3}{*}{\multicolumn{3}{|c|}{ Total }} & Count & 32 & 9 & 9 & 50 \\
\hline & & & $\%$ within BIRAD & $64.0 \%$ & $18.0 \%$ & $18 \%$ & $100.0 \%$ \\
\hline & & & $\%$ within $\mathrm{N}$ & $100.0 \%$ & $100.0 \%$ & $100.0 \%$ & $100.0 \%$ \\
\hline \multirow{5}{*}{\multicolumn{2}{|c|}{ T stage }} & \multirow[t]{3}{*}{1} & Count & 8 & 3 & 4 & 15 \\
\hline & & & $\%$ within $\mathrm{T}$ & $53.3 \%$ & $20.0 \%$ & $26.7 \%$ & $100.0 \%$ \\
\hline & & & $\%$ within $\mathrm{N}$ & $26.7 \%$ & $30.0 \%$ & $40.0 \%$ & $30.0 \%$ \\
\hline & & \multirow[t]{2}{*}{2} & Count & 22 & 7 & 6 & 35 \\
\hline & & & $\%$ within $\mathrm{T}$ & $62.9 \%$ & $20.0 \%$ & $17.1 \%$ & $100.0 \%$ \\
\hline
\end{tabular}




\begin{tabular}{||l|l|c|c|c|c||} 
& \% within N & $73.3 \%$ & $70.0 \%$ & $60.0 \%$ & $70.0 \%$ \\
\hline \multirow{3}{*}{ Total } & Count & 30 & 10 & 10 & 50 \\
\cline { 2 - 6 } & \% within T & $60 \%$ & $20.0 \%$ & $20.0 \%$ & $100.0 \%$ \\
\cline { 2 - 6 } & \% within N & $100.0 \%$ & $100.0 \%$ & $100.0 \%$ & $100.0 \%$ \\
\hline \hline
\end{tabular}

Table (3): Relation between breast tumor ER and PR status ,breast tumor Her2/neu status and axillary nodal metastasis

\begin{tabular}{|c|c|c|c|c|c|c|}
\hline & & & \multicolumn{3}{|c|}{$\mathbf{N}$} & \multirow[t]{2}{*}{ Total } \\
\hline & & & 0 & 1 & 2 & \\
\hline \multirow[t]{6}{*}{ Estrogen receptor(ER) } & \multirow{3}{*}{ Negative } & Count & 3 & 0 & 2 & 5 \\
\hline & & \% within ER & $60.0 \%$ & $0.0 \%$ & $40.0 \%$ & $100.0 \%$ \\
\hline & & \% within $\mathbf{N}$ & $9.1 \%$ & $0.0 \%$ & $22.2 \%$ & $10.0 \%$ \\
\hline & \multirow{3}{*}{ Positive } & Count & 30 & 8 & 7 & 45 \\
\hline & & \% within ER & $66.7 \%$ & $17.8 \%$ & $15.6 \%$ & $100.0 \%$ \\
\hline & & $\%$ within $\mathbf{N}$ & $90.9 \%$ & $100.0 \%$ & $77.8 \%$ & $90.0 \%$ \\
\hline \multirow{3}{*}{\multicolumn{2}{|c|}{ Total }} & Count & 33 & 8 & 9 & 50 \\
\hline & & \% within ER & $66.0 \%$ & $16.0 \%$ & $18 \%$ & $100.0 \%$ \\
\hline & & $\%$ within $\mathbf{N}$ & $100.0 \%$ & $100.0 \%$ & $100.0 \%$ & $100.0 \%$ \\
\hline \multirow[t]{6}{*}{ Progesterone receptor (PR) } & \multirow{3}{*}{ Negative } & Count & 5 & 1 & 5 & 11 \\
\hline & & \% within PR & $45.5 \%$ & $9.1 \%$ & $45.5 \%$ & $100.0 \%$ \\
\hline & & $\%$ within $\mathbf{N}$ & $15.6 \%$ & $11.1 \%$ & $55.6 \%$ & $22.0 \%$ \\
\hline & \multirow[b]{3}{*}{ Positive } & Count & 27 & 8 & 4 & 39 \\
\hline & & \% within PR & $69.2 \%$ & $20.5 \%$ & $10.3 \%$ & $100.0 \%$ \\
\hline & & $\%$ within $\mathbf{N}$ & $84.4 \%$ & $88.9 \%$ & $44.4 \%$ & $87.0 \%$ \\
\hline \multirow{3}{*}{\multicolumn{2}{|c|}{ Total }} & Count & 32 & 9 & 9 & 50 \\
\hline & & \% within PR & $64.0 \%$ & $18.0 \%$ & $18.0 \%$ & $100.0 \%$ \\
\hline & & \% within $\mathrm{N}$ & $100.0 \%$ & $100.0 \%$ & $100.0 \%$ & $100.0 \%$ \\
\hline \multirow[t]{6}{*}{ HER2 } & \multirow{3}{*}{ Negative } & Count & 33 & 8 & 5 & 46 \\
\hline & & \% within HER2 & $71.7 \%$ & $17.4 \%$ & $10.9 \%$ & $100.0 \%$ \\
\hline & & $\%$ within $\mathbf{N}$ & $91.7 \%$ & $88.9 \%$ & $100.0 \%$ & $92.0 \%$ \\
\hline & \multirow{3}{*}{ Positive } & Count & 3 & 1 & 0 & 4 \\
\hline & & \% within HER2 & $75.0 \%$ & $25.0 \%$ & $0.0 \%$ & $100.0 \%$ \\
\hline & & \% within $\mathbf{N}$ & $8.3 \%$ & $11.1 \%$ & $0.0 \%$ & $8.0 \%$ \\
\hline \multirow{3}{*}{\multicolumn{2}{|c|}{ Total }} & Count & 36 & 9 & 5 & 50 \\
\hline & & \% within HER2 & $72 \%$ & $18.0 \%$ & $10.0 \%$ & $100.0 \%$ \\
\hline & & $\%$ within $\mathbf{N}$ & $100.0 \%$ & $100.0 \%$ & $100.0 \%$ & $100.0 \%$ \\
\hline
\end{tabular}

There was statistically significant variation between the incidence of axillary nodal metastasis and the

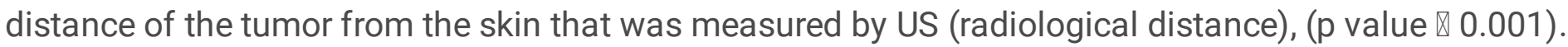
$\mathrm{ROC}$ analysis was done to detect the most accurate cut off distance of the tumor from the skin that was 
detected by $\mathrm{U} / \mathrm{S}$ and its relation with the axillary nodal metastasis. The analysis revealed that the most accurate cut off distance was at $2.6 \mathrm{~cm}$ from the skin that achieved sensitivity and specificity of $100 \%$ and 72.7, respectively. This means that early cancer breast with distance $\leq 2.6 \mathrm{~cm}$ from the skin are more likely to develop axillary lymph node metastasis, and those with tumors that are deep to this cut off level are less likely to have axillary nodal metastasis. ROC analysis also showed that the overall accuracy of $\mathrm{U} / \mathrm{S}$ in this test is $88.6 \%$. There was statistically significant difference between the incidence of axillary nodal deposits and the tumor distance from the skin that was measured by pathology (pathological

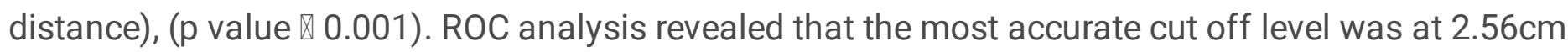
from the skin that achieved $100 \%$ sensitivity and $78.6 \%$ specificity (Figure 3 ).

17 patients of 50 had positive axillary lymph nodes, 8 of them were staged as $\mathrm{N} 1$ and the other 9 patients were staged as N2. There was a significant statistical difference between the radiological tumor distance and progression of axillary nodal metastasis from N1 to N2 stage, ( $p$ value $\otimes 0.014$ ). The ROC analysis showed that $2.25 \mathrm{~cm}$ radiological distance was the most accurate cut off distance from the skin that achieved $100 \%$ sensitivity and $60 \%$ specificity. There was a significant statistical variation between pathological distance and $\mathrm{N} 1$ to $\mathrm{N} 2$ progression of axillary lymph node metastasis, ( $p$ value $\otimes 0.001$ ). ROC analysis revealed that it was at $2.04 \mathrm{~cm}$ from the skin that achieved $83.3 \%$ sensitivity and $100 \%$ specificity, and $2.17 \mathrm{~cm}$ that achieved $86.3 \%$ sensitivity and $66.7 \%$ specificity.

\section{Discussion}

Status of axillary lymph node is one of the most important and reliable prognostic indicators and is an essential factor to detect staging and treatment of cancer breast cancer ${ }^{[1]}$.

Prediction of axillary nodal status before surgery is important for many reasons. It can prepare patients psychologically for ANLD if required in addition to it can assist with contingency planning for patients who desire immediate breast reconstruction. Accurate prediction of axillary lymph node status can avoid ANLD and its associated complications ${ }^{[7,8]}$.

The lymphatic drainage system of the breast is a rich plexus of vessels in the dermis and subareolar region suggesting that tumors located closer to the dermis and subareolar region are at high risk of lymphatic dissemination with high incidence of axillary nodal metastasis. The superficial lymphatic drainage described by Sappey, was located $3 \mathrm{~mm}$ depth from the skin ${ }^{[4,9]}$.

There are many clinical, histopathological, and molecular features have been related to the likelihood of axillary nodal metastases in patients with cancer breast ${ }^{[10-14]}$. Several nomograms have been initiated for the prediction of axillary lymph node metastasis, such as those developed at Memorial Sloan Kettering Cancer Center (MSKCC) and MD Anderson Cancer Center. These nomograms have specified several predictors of axillary nodal deposits such as: size of the tumor, age of the patient, anatomical location, lymphovascular invasion(LVI), histological type of the tumor, tumor grading, hormonal status 
of the tumor (ER and PR), in addition to focality and centricity of the tumor. These developed nomograms did not involve breast cancer distance from the skin and nipple -areola complex in their validation $[5,6,15]$.

In our study, 50 patients of early breast cancer $(\mathrm{T} 1, \mathrm{~T} 2)$ were involved in which they underwent breast conserving surgery. (46 patients) or modified radical mastectomy (4 patients), and for all the distance between the tumor and the skin was measured by US and then by the pathologist . 33 patients $(66 \%)$ were node negative and 17 patient (34\%) were node positive. N1 patients were $8(16 \%)$ and n2 patients were 9 patients (18\%). ANLD was done for all patients and the mean number of excised lymph nodes was 21.78. This compares well with the previous studies like, Cunningham et al., study that includes 209 patients. Of these, 61 (29\%) had axillary nodal metastasis, and 148 (71\%) had no known metastases and the study of Ansari et al. in which data were collected on 233 early breast cancer patients, of which 177 (76\%) were node negative and $56(24 \%)$ were node positive ${ }^{[4,5]}$.

The mean age of the patients in our study was $51.87 \pm 6.48$ for node negative patients, $46.78 \pm 4.73$ for $n 1$ patient group, and $52.67 \pm 8.57$ for $\mathrm{n} 2$ patient group. Eom et al., reported that the mean age for node negative patients is $\mathbf{5 1 . 0 7}$ group, and for node positive patients is 48.69 while Ansari et al., reported that the mean age of all patients was 66.2 years while the mean age for node negative and positive patients was 66.9 and 63.9 , respectively $[16,5]$. In our study there was no statistically significant difference between the age of the patient and the incidence of axillary nodal metastasis ( $p$ value $=0.165$ ). Cunningham et al., reported similar result and declared there was no statistical significant variation between the age of the patient and the incidence of axillary lymph node metastasis, $(p \text { value }=0.399)^{[4]}$.

In our study there was no significant statistical variation between the location of the tumor and incidence of axillary lymph node deposits, ( $p$ value $=0.185$ ). This compares well with the study of Cunningham et al., that revealed there was no significant statistical variation between the tumor location and incidence of axillary nodal metastasis, ( $p$ value $=0.138$ ) [4]. However some studies like Ansari et al., showed that there was a significant statistical variation between the tumor location and incidence of axillary lymph node metastasis, $(p$ value $=0.001)$. This may be explained by sample size difference ${ }^{[5]}$.

In our study there was no statistically significant variation between size of the tumor and the incidence of axillary nodal metastasis, ( $p$ value $=0.758$ ). Mean tumour size in our study was $2.65 \mathrm{~cm}$. Eom et al., reported that the mean tumor size for node negative and positive patients was 1.92 and $2.76 \mathrm{~cm}$, respectively and this matching with our result that there was no statistically significant relation between the tumor size $(T)$ and incidence of axillary lymph node metastasis, $(p \text { value }=0.709)^{[16]}$. Other studies reported different data like Ansari et al., in which the mean tumor size for all patients was $1.34 \mathrm{~cm}$ and it was $1.24 \mathrm{~cm}$ and 1.68 for node negative and positive patients, respectively and showed significant statistical difference between the size of tumor and incidence of axillary nodal metastasis. Patients T1c and T2 stages were 7.7 and 8.6 times more likely to have positive nodes, respectively than patients with $\mathrm{T} 1 \mathrm{a}$ and T1b stages, $(\mathrm{p} \text { value }=0.001)^{[5]}$. Cunningham et al., reported that tumors in the node positive patients tended to be larger $(P \text { value }=0.002)^{[4]}$. 
In our study no significant statistical difference was observed for ER, PR, or HER2 status and axillary LN positivity, ( $p$ value $=0.267,0.124,0.542$ ) respectively. This similar to the study reported by Eom et al., IN which there is no significant variations were observed for ER, PR, or HER2 statuses between patients with positive and negative axillary $L N(p$ value $=0.478,0.534,0.422)$ respectively ${ }^{[16]}$. Ansari et al. showed also that there were no significant variation noted for ER, PR, or HER2 statuses between patients with positive and negative axillary nodes, $(p$ values $=1.0,0.14,1.0)$ respectively ${ }^{[5]}$.

In this study, it was found that there is a statistically significant correlation between the incidence of axillary LN metastasis and the breast cancer distance from the skin as measured by US, ( $p$ value $\nabla$ 0.001 ), and the most accurate cut off level, was at $2.6 \mathrm{~cm}$ from the skin that achieved $100 \%$ sensitivity and $72.7 \%$ specificity. Also, it was noted that there was a statistically significant correlation between the incidence of axillary LN metastasis and breast cancer distance from the skin as measured by the pathological assessment, ( $p$ value $\nabla 0.001$ ), and the most accurate cut off level, was at $2.56 \mathrm{~cm}$ from the skin that achieved $100 \%$ sensitivity and $78.6 \%$ specificity. It was obvious in our study that no patient with cancer deep to $2.6 \mathrm{~cm}$ from the skin had any positive axillary LNs. This means that $2.6 \mathrm{~cm}$ is the most likely cut off distance at which positive axillary LNs is to be predicted. Eom et al., reported that patients with cancer breast closer to the skin are more likely to develop positive axillary LNs than those with tumor far from the skin, (P value $=0.047)^{[16]}$. This also compared well with Ansari et al., who reported that closer proximity of the cancer to the skin was associated with positive axillary LNs and each $1 \mathrm{~mm}$ decrease in the cancer distance from the skin was associated with a 15\% increased likelihood of lymph node metastasis ${ }^{[5]}$. Ansari et al., studied also the relationship between the size of the largest metastatic axillary LN and the breast cancer distance from the skin and reported that there was no statistically significant association between the size of the largest LN metastasis and distance from the skin, ( $p$ value $=0.72$ ) and also there was no significant statistical correlation between the number of positive axillary LNs and the distance of the tumor from the skin, $(P$ value $=0.29){ }^{[5]}$.

Our study revealed that there was a statistically significant relation between the cancer proximity from the skin as detected by U/S and progression of axillary LN metastasis from N1 to N2 stage, ( $p$ value $\nabla 0.014$ ) and the most accurate cut off distance of the tumor from the skin at which progression of from $\mathrm{N} 1$ to N2 stage was most likely to occur was at $2.25 \mathrm{~cm}$ that achieved $100 \%$ sensitivity and $60 \%$ Specificity. Regarding pathological measurements we also found that there was a significant statistical correlation between the cancer distance from the skin as measured by pathology, and axillary LN metastasis progression from N1 to N2 stage, ( $p$ value $\nabla 0.001$ ) and the most accurate cut off distance was between $2.04 \mathrm{~cm}$ that achieved $83.3 \%$ sensitivity and $100 \%$ specificity, and $2.17 \mathrm{~cm}$ that achieved $86.3 \%$ sensitivity and $66.7 \%$ specificity.

We also compared radiological measurement (U/S) with the pathological measurements of the breast cancer distance from the skin in order to clarify the accuracy of U/S in detecting this distance. We found that the mean distance between the breast cancer and the skin that was measured by U/S was $2.575 \mathrm{~cm}$, while the mean distance that was measured by pathology was $2.65 \mathrm{~cm}$. The mean difference between

Page $11 / 16$ 
both measurements was only $0.075 \mathrm{~mm}$. There was no significant statistical variation between the 2 methods of measurement, ( $p$ value $=0.647$ ). The overall accuracy of the US in this test was $88.6 \%$. This means that $\mathrm{U} / \mathrm{S}$ is considered to be a reliable investigating method detection of the distance between the breast cancer and the surface of the skin.

There is some limitations of this study that have to be addressed including technical factors that could have affected the distance from the skin i.e the scan technique and ability of the ultrasonography physician to obtain the proper image through the image plane that most accurately evaluate proximity of the tumor to the skin surface which may result in induced ultrasound measurement error. Some tumors had poorly defined edges, and others had hyperechoic halos surrounding the tumor, ultrasound characteristics that make accurate measurements are more difficult to obtain.

The size of breast was not involved in this study, and the relation between tumor size and breast size may influence proximity to the skin, especially in smaller breasts and it is well known that distance from the skin is shorter in smaller breasts than in larger breasts; therefore, effect of breast size on nodal metastases cannot be excluded. Sample size of the patients was small which was also a limiting factor, so further prospective studies with larger patient numbers and a standardized US protocol would be required.

Ultimately, in the future, we may be looking to detect which patients are able to avoid any axillary surgery including sentinel lymph node biopsy (SLNB).

\section{Conclusion}

Cancer distance from the skin should be taking into consideration when preoperatively evaluating a patient with breast cancer before surgery and assessing the risk of axillary nodal deposits.

\section{List Of Abbreviations}

US: Ultrasonography

ER: Estrogen receptor

PR: Progesterone receptor

ANLD: Axillary lymph node dissection

MKSCC: Memorial Sloan Kettering Cancer Center

LN: Lymph node

BIRAD: Breast ImagingReporting and Data System 


\section{Declarations}

Acknowledgements:

Not applicable

Ethical approval and consent to participate:

This data collection and the consent to participate were approved by the Ethical Committee of Benha Faculty of Medicine (No: RC.2.3.2020).

Consent for publication:

Written consent was obtained for publication of this study.

Availability of supporting data:

The datasets used and/or analysed during the current study available from the corresponding author on reasonable request.

Competing Interest:

There is no conflict of interest to disclose

Funding:

There are no sources of funding to acknowledge

Authors' contributions: All authors read and approved the manuscript

ME: Study concept, design, data collection, interpretation, literature review, writing.

MZ: data collection, interpretation, literature review, writing.

KA: Data collection, writing.

MF: Data collection, writing.

RA: Data collection, writing.

\section{References}

1-Colleoni M, Zahrieh D, Gelber RD, Holmberg SB, Mattsson JE, Rudenstam CM, et al. Site of primary tumor has a prognostic role in operable breast cancer: The international breast cancer study group experience. J ClinOncol. 2005;23(7):1390- 1400. 
2-Rietman JS, Dijkstra PU, Geertzen JH, Baas P, De Vries J, Dolsma W, et al. Short term morbidity of the upper limb after sentinel lymph node biopsy or axillary lymph node dissection for Stage I or II breast carcinoma. Cancer: Interdisciplinary International Journal of the American Cancer Society. 2003;98(4):690-696.

3-Giuliano AE, Hunt KK, Ballman KV, Beitsch PD, Whitworth PW, Blumencranz PW, et al. Axillary dissection vs no axillary dissection in women with invasive breast cancer and sentinel node metastasis: a randomized clinical trial. Jama. 2011;305(6):569-575.

4- Cunningham JE, Jurj $A L$, Oman $L$, Stonerock $A E$, Nitcheva $D K$, Cupples $T E$. Is risk of axillary lymph node metastasis associated with proximity of breast cancer to the skin?.Breast cancer research and treatment. 2006;100(3):319-328.

5-Ansari B, Morton MJ, Adamczyk DL, Jones KN, Brodt JK, Degnim AC, et al. Distance of breast cancer from the skin and nipple impacts axillary nodal metastases.Annals of surgical oncology. 2011;18(11):3174-3180.

6-Veerapong J, Boughey JC, Mittendorf EA, Harrell R, Bassett R, Ross M, et al.A validated risk assessment of sentinel lymph node involvement in breast cancer patients. Ann SurgOncol. 2011;18:S59 (Abstract).

7- Silverstein MJ, Skinner KA, LomisTJ.Predicting axillary nodal positivity in 2282 patients with breast carcinoma. World journal of surgery. 2011;25(6):767-772.

8-Giuliano AE, McCall L, Beitsch P, Whitworth PW, Blumencranz P, Leitch AM, etal.Locoregional recurrence after sentinel lymph node dissection with or without axillary dissection in patients with sentinel lymph node metastases: the American College of Surgeons Oncology Group Z0011 randomized trial. Annals of surgery. 2010;252(3):426.

9-Suami H, Pan WR, Taylor GI.Historical review of breast lymphatic studies. Clinical Anatomy: The Official Journal of the American Association of Clinical Anatomists and the British Association of Clinical Anatomists. 2009;22(5):531-536.

10-Rahusen FD, Torrenga H, Van Diest PJ, Pijpers R, Van Der Wall E, Licht J, et al. Predictive factors for metastatic involvement of nonsentinel nodes in patients with breast cancer. Arch Surg. 2001;136:10591063.

11-Cavalli LR.Molecular markers of breast axillary lymph node metastasis. Expert Rev MolDiagn. 2009;9:441-454.

12-Lee JH, Kim SH, Suh YJ, Shim BY, Kim HK. Predictors of axillary lymph node metastases (ALNM) in a Korean population with T1-2 breast carcinoma: triple negative breast cancer has a high incidence of ALNM irrespective of the tumor size. Cancer Res Treat. 2010;42:30-36. 
13-Rivadeneira DE, Simmons RM, Christos PJ, Hanna K, Daly JM, Osborne MP. Predictive factors associated with axillary lymph node metastases in T1a and T1b breast carcinomas: analysis in more than 900 patients. J Am Coll Surg. 2000;191:1-6.

14-Patani NR, Dwek MV, Douek $M$. Predictors of axillary lymph node metastasis in breast cancer: a systematic review. Eur J SurgOncol. 2007;33:409-419.

15-Bevilacqua JL, Kattan MW, Fey JV, Cody III HS, Borgen PI, Van Zee KJ. Doctor, what are my chances of having a positive sentinel node? A validated nomogram for risk estimation.Journal of clinical oncology. 2007;25(24):3670-3679.

16-Eom YH, Kim EJ, Chae BJ, Song BJ, Jung SS.The distance between breast cancer and the skin is associated with axillary nodal metastasis. Journal of surgical oncology. 2015;111(7):824-828.

\section{Figures}

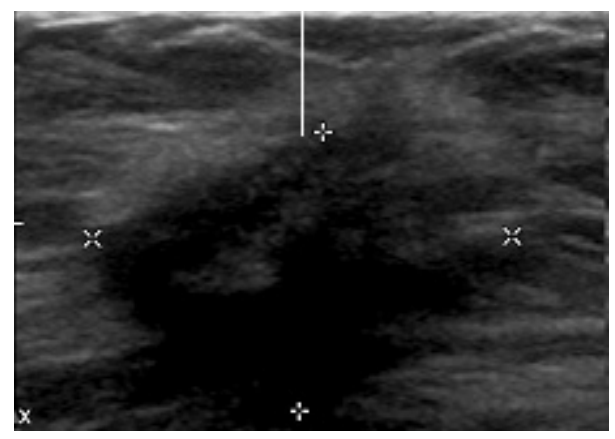

Figure 1

Distance of cancer breast from the skin by U/S (white line)

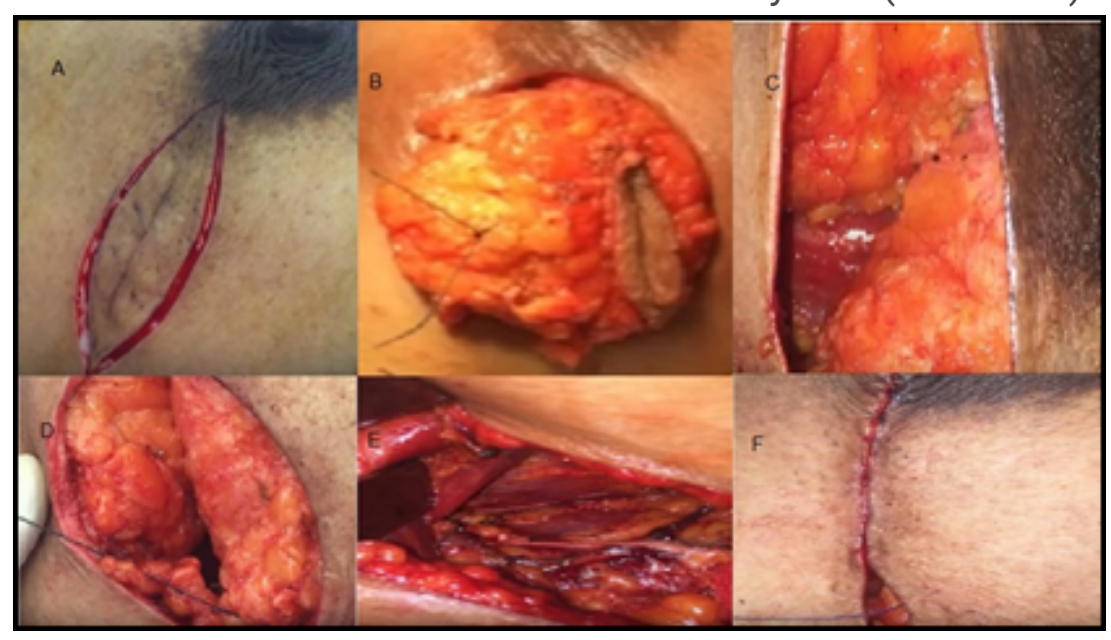

Figure 2

BCS (A) elliptical incision, (B) Orientation of specimen, (C) Mobilization of breast pillar, (D) Suturing of pillars, (E) Axillary clearance and (D) Suturing of the skin. 

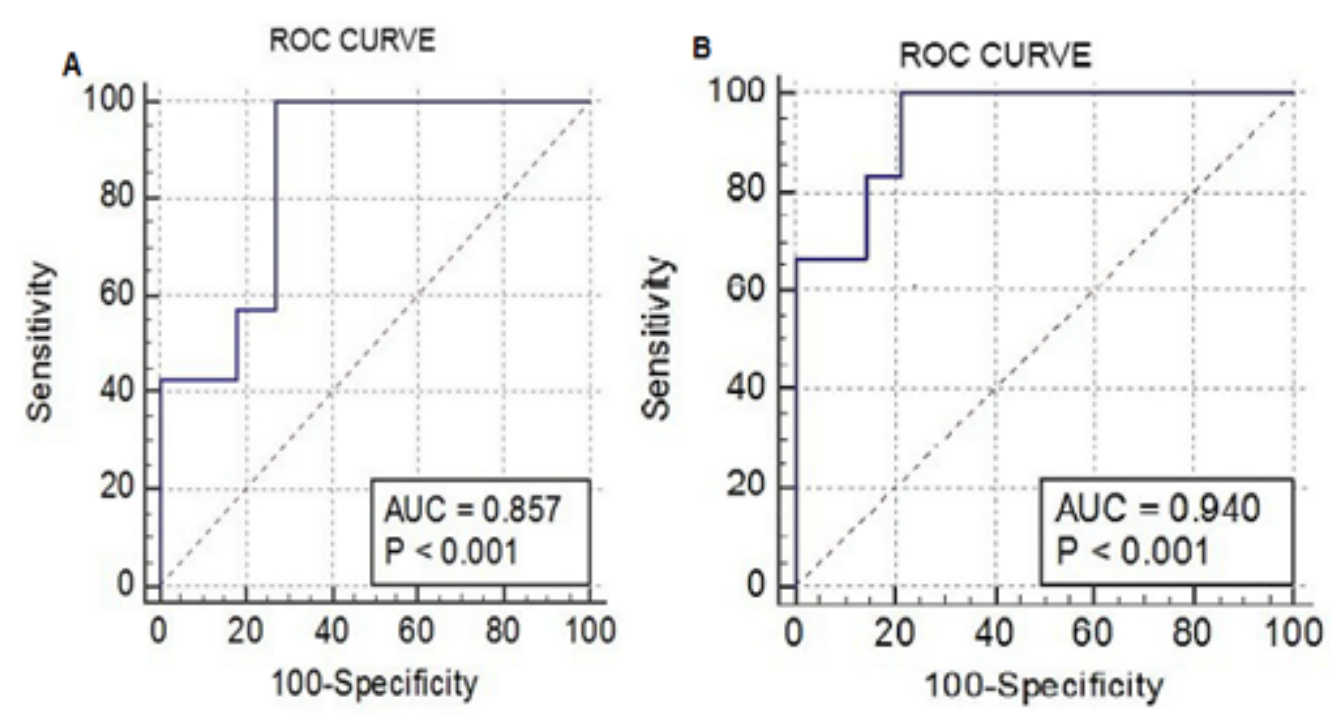

Figure 3

ROC analysis of axillary nodal metastasis (A) radiological distance, (B) pathological distance.
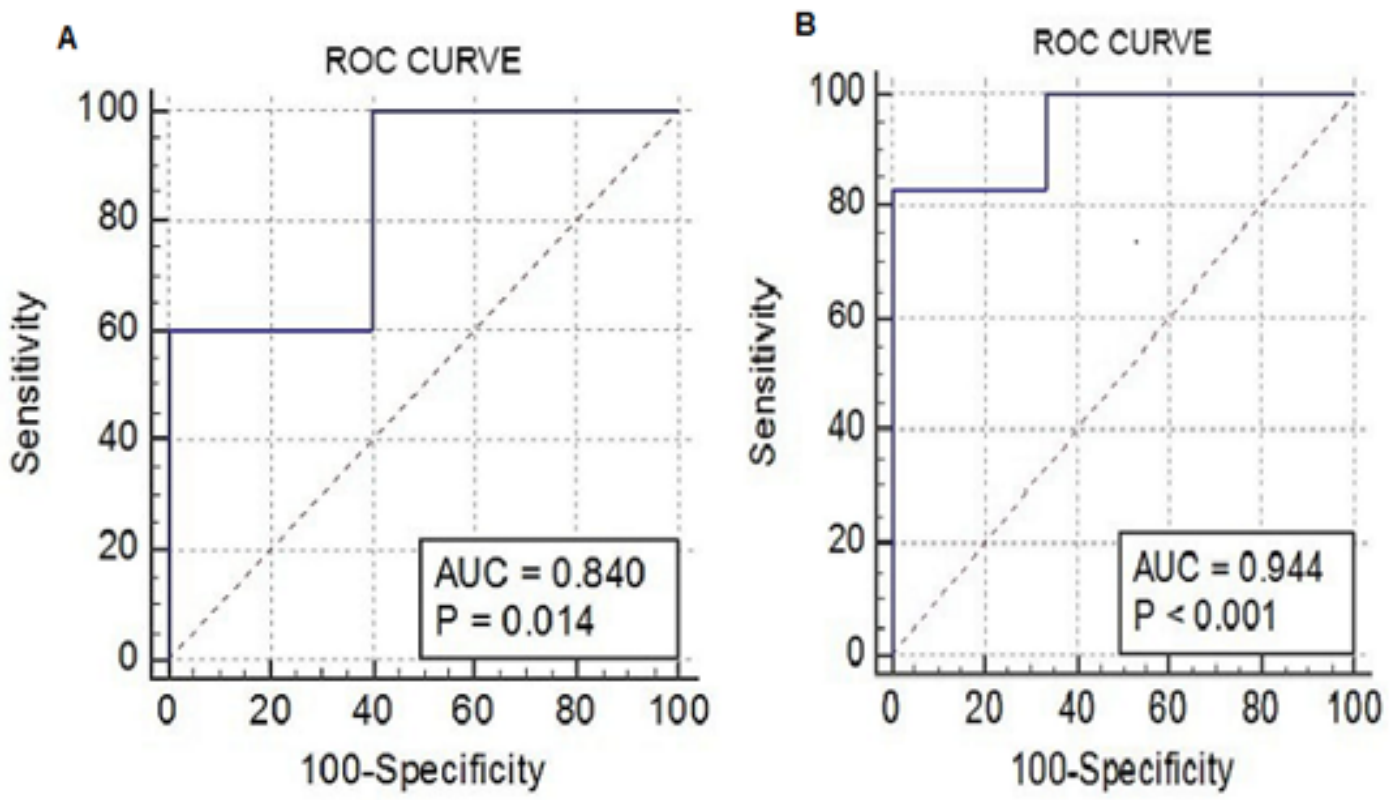

Figure 4

ROC analysis of axillary nodal metastasis progression from N1 to N2 (a) radiological distance, (b) pathological distance. 